\title{
Box-and-whiskers plots
}
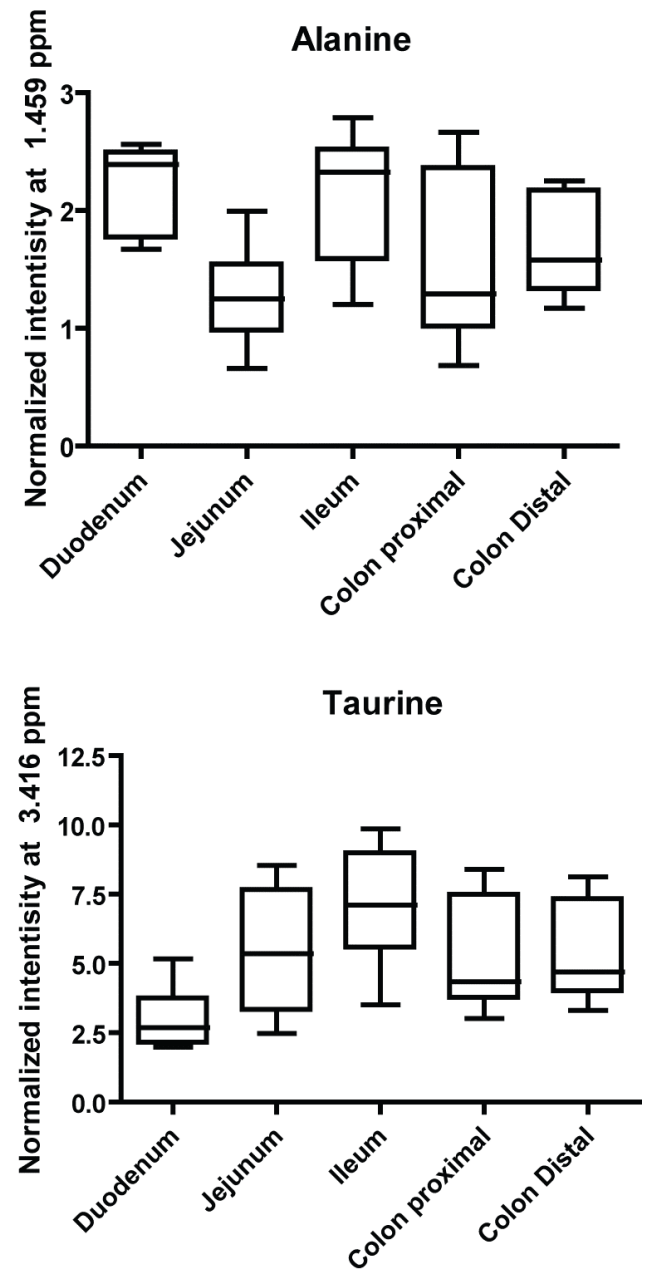

Supplementary Figure 1: Comparison of area normalized intensities of alanine ( $\delta 1.459)$ and taurine ( 83.416$)$ obtained from ${ }^{1} \mathrm{H}$ CPMG MAS NMR metabolic profiles of germ-free duodenum, jejunum, ileum, proximal and distal colon displayed using box-and-whisker plots ( $\mathrm{n}=8 /$ group). 

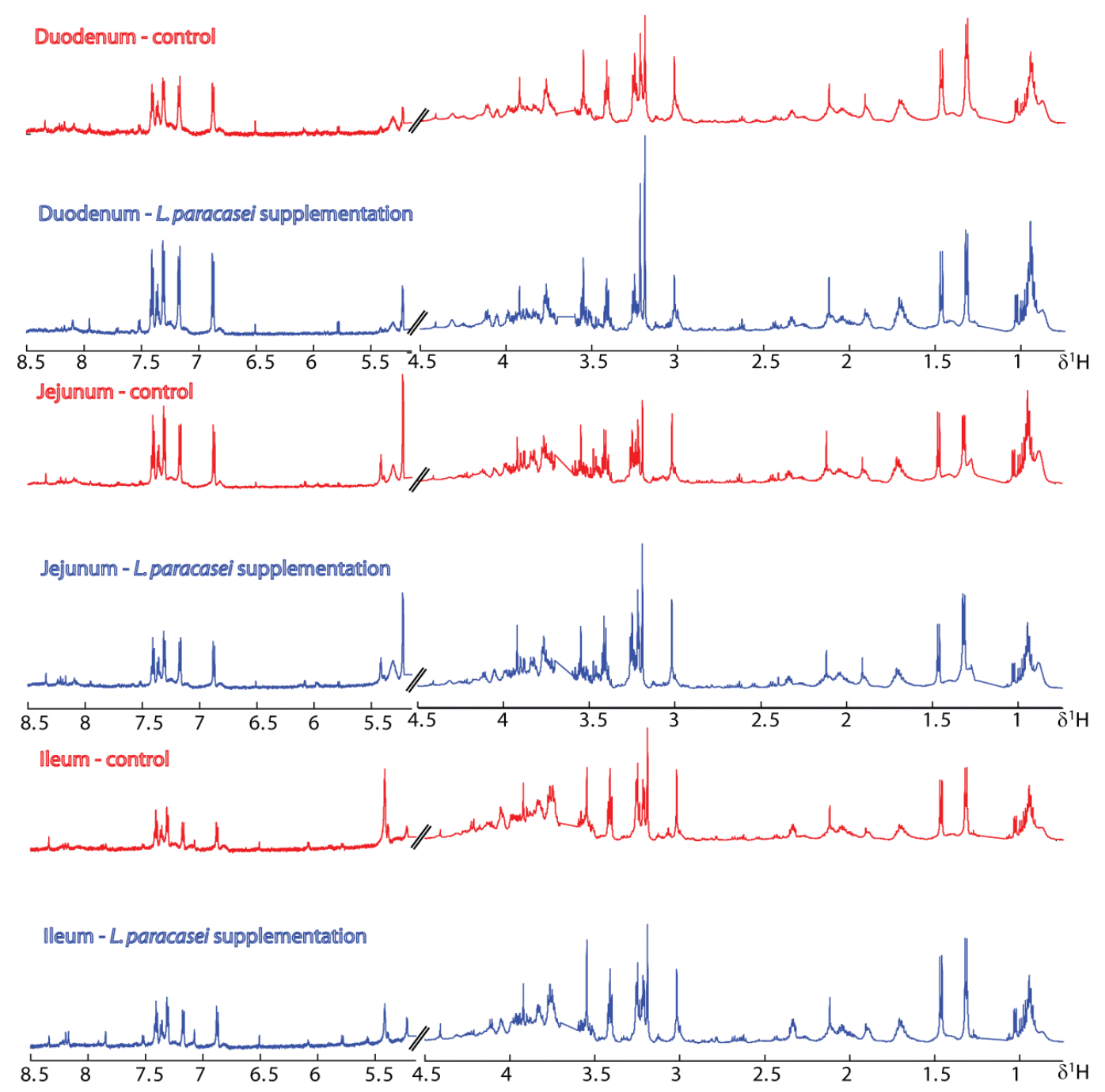

Supplementary Figure 2: $600 \mathrm{MHz}{ }^{1} \mathrm{H}$ CPMG MAS NMR spectra of the aliphatic region ( $\delta 4.5-0.75)$ and aromatic region $(\delta 8.5-5.15)$ from gnotobiotic tissues (duodenum, jejunum, and ileum) obtained from control germ-free animals and germfree mice supplemented with live $L$. paracasei. The vertical scale for the aromatic region is 8 times higher than the aliphatic region. 